\title{
SCADDOC
}

Infer, Interpret \& Inspire Science

International Journal of Dentistry and Oral Science (IJDOS)

ISSN: $2377-8075$

\section{Measurement Of Surface Dose To The Thyroid Gland In Intraoral Radiography}

Research Article

Priyadarshini $\mathrm{SK}^{1 *}$, Sathasivasubramanian $\mathrm{S}^{2}$, Murali $\mathrm{V}^{3}$

${ }^{1}$ Lecturer, Department of Oral Medicine \& Radiology, Dhanalakshmi Srinivasan Dental College and Hospitals, Perambalur - 621113, India.

${ }^{2}$ Former HOD - Department of Oral Medicine \& Radiology and Former Vice-principal - Sri Ramachandra Faculty of Dental sciences, Sri Ramachandra University, Porur, Chennai - 600116, India.

${ }^{3}$ Chief Medical Physicist cum RSO, Apollo Speciality Hospitals, 320 Padma complex, Teynampet, Chennai- 600035, India.

\section{Abstract}

Background: Intra-oral periapical radiographs are the most frequently requested radiographic examination and an indispensable tool in the diagnosis of dental diseases. The repeated exposures to these radiographic examinations pose a risk especially to the thyroid gland due to the proximity to dental structures. This study was conducted to evaluate the surface dose received by the thyroid gland during intra-oral periapical (IOPA) radiographic exposures.

Aim: To measure the entrance surface dose to the thyroid gland and compare the mean surface dose received by the thyroid during maxillary and mandibular anterior \& posterior intraoral periapical radiography.

Materials \& methods: The study comprised 64 participants. Thermoluminiscent dosimeter (TLD) cubes were used to measure the surface dose to the thyroid gland. The dose recorded by the TLD-s were measured using Harshaw 4500 TLD reader. Results: The mean surface dose to the thyroid gland was high during maxillary anterior and posterior quadrants compared to mandibular anterior and posterior radiographic exposures.

Conclusion: The surface dose received by the thyroid gland during intraoral radiography may be considered low but the frequency of such exposures may pose a risk to the radiosensitive thyroid gland. Therefore, the thyroid gland should be protected during routine IOPA radiographic techniques.

Keywords: Thyroid Surface Dose; Dosimetry; Thermoluminescent Dosimeter; Intra-Oral Periapical Radiography.

\section{Introduction}

Imaging plays an integral part in the diagnosisand treatment planning in dental practice.Dental radiographs comprise the most frequent diagnostic radiographic examination [1] and among them intra oral radiographs are the most common and frequently taken radiographs.[2] The purpose of these examinations range from diagnostic, restorative purpose, to treatment planning and follow up. Although the exposure from dental x-rays are minimal the radiographic examination should be justified and the principle of "As low as reasonably achievable" should be followed as repeated exposure to low-dose radiation may also result in deleterious stochastic effects. The salivary glands and the thyroid gland are considered the organs at risk in dental radiographyas they are close to the dental structures. Particularly the thyroid gland is the prime and most radiosensitive organ in dental radiography especially during intra-oral radiography of the maxillary anterior region as it is present within the primary x-ray beam and has high susceptibility to radiation induced carcinogenesis. [3, 4] Although it is considered that the radiation dose from dental radiology is minimal the unwarranted and repeated exposure of this gland during dental radiographic procedures may lead to thyroid dysfunction resulting in autoimmune thyroiditis and papillary thyroid carcinoma in young women and also thyroid cysts in women of all ages.[3] Although with increasing age at exposure the risk of radiation induced thyroid cancer decreases, [5] thyroid protection is recommended in dental radiography when it does not interfere with the exposure and the quality of the image.[6]

The aim of the study is to measure the entrance surface dose to the thyroid during intra oral periapical (IOPA) radiographic

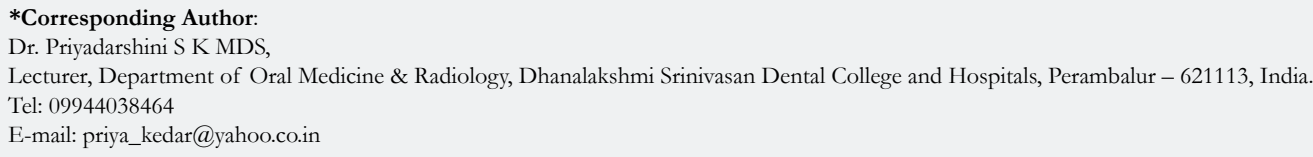

Copyright: Dr. Priyadarshini S K MDS ${ }^{\circ} 2021$. This is an open-access article distributed under the terms of the Creative Commons Attribution License, which permits unrestricted use, distribution and reproduction in any medium, provided the original author and source are credited. 
procedures.

By measuring and comparing the entrance surface radiation dose to the thyroid gland in intra oral periapical radiographic exposures of the different quadrants we come to know the amount of radiation that will reach the thyroid gland, and stress upon the need for protecting the thyroid gland in routine dental practice.This study will give us more knowledge on the surface dose to the thyroid gland in routine diagnostic intra oral periapical radiographic exposures.

\section{Materials And Methods}

This was an observational study. Institutional ethical approval was obtained prior to the study. A total of 64 subjects participated in the study.Subjects were chosen so that they are equally distributed in maxillary and mandibular posterior quadrants in right and left side and in maxillary and mandibular anterior regions. Thermoluminescent dosimeter (TLD) 100 (LiF:Mg,Ti) cubes of size $3 \mathrm{~mm}$ x $3 \mathrm{~mm} \times 1 \mathrm{~mm}$ sealed and numbered in plastic foils were usedto measure the entrance surface dose. Adult size 2, E speed films and Satelec X-Mind intra oral x ray machine, circular collimator with $70 \mathrm{Kvp}, 8 \mathrm{~mA}$ was used for the study. Patients above the age of 20 years only were included in the study. Patients were not subjected to any additional radiation and only those patients who were requested for a diagnostic radiograph were included. Pregnant and trauma patients were excluded from the study. The details of the patient, the TLD number respective to the right and left side was noted in the proforma tailored for the study.

The location of the thyroid gland was noted and two TLD's were placed over the thyroid collar with an adhesive tape in relation to the right and left lobe of the thyroid respectively. The x-rays were exposed using bisecting angle technique and the exposure time for the anterior teeth was set to 0.6 seconds and for the posterior teeth 0.8 seconds. After making the exposure the dose received by the TLD was measured using Harshaw 4500 TLD reader. The readings were done within 24 hours after exposure and the exposed TLD-s were annealed before re-using.

\section{Results}

Statistical Analysiswas done using Independent t-test for comparing the mean between the different groups. The mean surface dose in anterior quadrants was $0.626 \mathrm{mGy}$ and in posterior quadrants was $0.669 \mathrm{mGy}$. On comparing the mean dose to the posterior and anterior regions the $\mathrm{P}$ value is 0.757 which is not statistically significant (Table 1). The mean dose during the maxillary anterior exposures was $0.755 \mathrm{mGy}$ and during the mandibular anterior exposures was $0.498 \mathrm{mG}$. On comparing the mean between the upper and the lower anterior exposures the $\mathrm{P}$ value was 0.118 which was not statistically significant (Table 2). The mean surface dose in relation to the maxillary posterior was $0.763 \mathrm{mGy}$ and in mandibular posterior was $0.574 \mathrm{mGy}$. On comparing the mean doses, the $\mathrm{P}$ value was 0.399 which was statistically not significant (Table 3). The mean surface dose in Right maxillary posterior was $0.659 \mathrm{mGy}$, Right mandibular posterior was $0.443 \mathrm{mGy}$ with a $\mathrm{P}$ value of 0.387 which was not statistically significant. The mean surface dose to the Left maxillary posterior was $0.867 \mathrm{mGy}$ and left mandibular posterior was $0.706 \mathrm{mG}$ with a $\mathrm{P}$ value of 0.675 which was not statistically significant (Table 4).

\section{Discussion}

Dental radiographs are an effective and imperative aid in the diagnosis and management of various dental and oral diseases. Although the radiation dose received from dental radiography is low, low dose is not considered "safe dose" and a higher lifetime prevalence and frequency of exposure can result in deleterious stochastic effects, especially to the thyroid gland due its high ra-

Table 1. Mean Surface Dose To Thyroid In Anterior And Posterior Quadrants.

\begin{tabular}{|c|c|c|c|c|}
\hline \multirow{2}{*}{ GROUP } & \multirow{2}{*}{$\begin{array}{l}\text { NUMBER OF } \\
\text { EXPOSURES }\end{array}$} & MEAN & \multirow{2}{*}{$\begin{array}{l}\text { STANDARD } \\
\text { DEVIATION }\end{array}$} & \multirow{2}{*}{ P VALUE } \\
\hline & & (in $\mathrm{mGy}$ ) & & \\
\hline ANTERIOR & 32 & 0.626 & 0.461 & \multirow{2}{*}{0.757} \\
\hline POSTERIOR & 32 & 0.669 & 0.621 & \\
\hline
\end{tabular}

Table 2. Mean Surface Dose To Thyroid In Maxillary And Mandibular Anterior Quadrants.

\begin{tabular}{|c|c|c|c|c|}
\hline \multirow{2}{*}{ GROUP } & \multirow{2}{*}{$\begin{array}{l}\text { NUMBER OF } \\
\text { EXPOSURES }\end{array}$} & MEAN & \multirow{2}{*}{$\begin{array}{l}\text { STANDARD } \\
\text { DEVIATION }\end{array}$} & \multirow{2}{*}{ P VALUE } \\
\hline & & (in $\mathrm{mGy}$ ) & & \\
\hline $\begin{array}{l}\text { MAXILLARY } \\
\text { ANTERIOR }\end{array}$ & 16 & 0.755 & 0.521 & \multirow{2}{*}{0.118} \\
\hline $\begin{array}{c}\text { MANDIBULAR } \\
\text { ANTERIOR }\end{array}$ & 16 & 0.498 & 0.366 & \\
\hline
\end{tabular}

Table 3. Mean Surface Dose To Thyroid In Maxillary And Mandibular Posterior Quadrants.

\begin{tabular}{|c|c|c|c|c|}
\hline \multirow{2}{*}{ GROUP } & NUMBER OF & MEAN & STANDARD DE- & \multirow{2}{*}{ P VALUE } \\
& EXPOSURES & (in mGy) & VIATION & \\
\hline MAXILLARY POSTERIOR & 16 & 0.763 & 0.595 & \multirow{2}{*}{0.399} \\
\hline MANDIBULAR POSTERIOR & 16 & 0.574 & 0.651 & \\
\hline
\end{tabular}


Table 4. Mean Surface Dose To Thyroid In Right And Left Maxillary And Mandibular Posterior Quadrants.

\begin{tabular}{|c|c|c|c|c|}
\hline GROUP & $\begin{array}{c}\text { NUMBER OF EXPO- } \\
\text { SURES }\end{array}$ & $\begin{array}{l}\text { MEAN } \\
\text { (in } \mathrm{mGy} \text { ) }\end{array}$ & $\begin{array}{l}\text { STANDARD } \\
\text { DEVIATION }\end{array}$ & P VALUE \\
\hline RIGHT MAXILLARY POSTERIOR & 8 & 0.659 & 0.462 & \multirow{2}{*}{0.387} \\
\hline RIGHT MANDIBULAR POSTREIOR & 8 & 0.443 & 0.506 & \\
\hline LEFT MAXILLARY POSTREIOR & 8 & 0.867 & 0.721 & \multirow{2}{*}{0.675} \\
\hline LEFT MANDIBULAR POSTERIOR & 8 & 0.706 & 0.782 & \\
\hline
\end{tabular}

dio-sensitivity and anatomic position. The only established environmental risk factor for developing thyroid cancer is exposure to moderate to high dose ionizing radiation. Repeated exposure to low doses of ionizing radiation by dental radiographs has also been associated with an increased risk of thyroid abnormalities and thyroid cancer. $[3,7]$ Thus it is important for the dental practitioner to justify the need of dental x-ray and optimise the patient dose to ensure radiation protection.

In the present study the surface dose at the level of thyroid region was evaluatedin routine diagnostic singlediagnostic intra oral periapical radiograph of anterior and posterior quadrants and their mean dose was compared.TLD-100 (LiF:Mg,Ti) was used for measuring the dose, which is the recommended and most commonly used thermoluminescent material for measuring the entrance surface dose.[8] For the posterior IOPA exposures, the dose received by the TLD nearest to the $\mathrm{x}$ ray source was taken for statistical analysis, as the dose to the thyroid gland is mainly related to the direction of the $\mathrm{x}$-ray source.[9] For the anterior IOPA exposure, the maximum dose received was considered for statistical analysis.

According to the International Commission on Radiological Protection (ICRP) the reference level for the entrance surface dose in intra oral periapical radiography is $7 \mathrm{mGy}$.[10]

In this study the mean entrance surface dose to the thyroid gland in maxillary anterior and posterior IOPA exposures was high compared to the mandibular quadrants.However, the difference in the mean doses was not statistically significant.The mean surface dose to the thyroid in this study was also less compared to the results of the previous studies carried out in intra-oral radiography. Mortazavi et al measured the surface dose to the skin for the maxillary and mandibular IOPA exposures using 70Kvp, $7 \mathrm{~mA}$ with exposure time of 0.16 to 0.41 seconds to be ranging from 0.01 to $0.40 \mathrm{mG}$. [11] B.Poppe et al reported the entrance surface dose in intra oral periapical radiographic exposures with $50 \mathrm{Kv}$ to $70 \mathrm{Kv}$ to be ranging from 1.2 to $2.7 \mathrm{mGy}$. [12] Sheikh et al calculated the entrance surface dose to the thyroid using pocket dosimeter in full mouth intra oral periapical radiography by the bisecting angle technique to be $1.093 \mathrm{mGy}$ and maxillary occlusal radiography to be $0.15 \mathrm{mG}$. The surface dose to the thyroid at the level of right lobe was $1.39 \mathrm{mGy}$ and at the level of the left lobe was $1.2 \mathrm{mG}$. The exposure parameters that they used was $65 \mathrm{Kvp}$, $10 \mathrm{~mA}$ at 1 second. [13] Jibiri et al measured the entrance surface dose to the skin of the eyes, parotid glands and thyroid gland during intra oral radiography. The mean entrance surface dose to the thyroid gland was $0.1869 \pm 0.082 \mathrm{mGy}$. [14]

In this study, the entrance surface dose to the thyroid during anterior IOPA ranged from $0.106 \mathrm{mG}$ y to $1.848 \mathrm{mGy}$ and the sur- face dose during posterior IOPA ranged from $0.126 \mathrm{mGy}$ to 1.997 mGy.

The entrance surface dose to the thyroid in maxillary anterior ranged from $0.203 \mathrm{mGy}$ to $1.848 \mathrm{mGy}$ and maxillary posterior region ranged from $0.143 \mathrm{mG}$ to $1.917 \mathrm{mG}$.

The entrance surface dose to the thyroid in mandibular anterior ranged from $0.106 \mathrm{mGy}$ to $1.229 \mathrm{mGy}$ and mandibular posterior ranged from $0.126 \mathrm{mGy}$ to $1.997 \mathrm{mG}$.

Most of the previous studies have evaluated the entrance surface dose to the thyroid, using panoramic radiography and full mouth intra oral periapical radiography however there is no data evident about comparison of the entrance surface dose to the thyroid in anterior and posterior intra oral periapical radiography in patients. In the present study, the entrance surface dose to thyroid gland was measured for single diagnostic intra oral periapical radiograph of anterior and posterior quadrants and their mean dose was compared.

\section{Conclusion}

The results of the study reveal that the surface dose at the thyroid level in intraoral periapical radiography is well below the reference level given by ICRP 2001. However, repeated exposure to low dose radiation such as dental $\mathrm{x}$-rays cannot be neglected. Owing to the high radiosensitivity of the thyroid gland and it's position - regardless of the region exposed, the thyroid gland has to be protected in routine dental practice.

\section{References}

[1]. Horner K. Radiation protection in dental radiology. Brit J Radiol. 1994 Nov;67(803):1041-9.

[2]. Kalinowski P, Rózyło-Kalinowska I, Rózyło TK. Demographic structure of patients taking dental X-rays in the Lublin region. Ann Univ Mariae Curie Sklodowska Med. 2001;56:431-5. PubMed PMID: 11977354.

[3]. Memon A, Godward S, Williams D, Siddique I, Al-Saleh K. Dental xrays and the risk of thyroid cancer: a case-control study. Acta Oncol. 2010 May;49(4):447-53. PubMed PMID: 20397774.

[4]. Crane GD, Abbott PV. Radiation shielding in dentistry: an update. Aust Dent J. 2016 Sep;61(3):277-81. PubMed PMID: 26644147.

[5]. Kleinerman RA. Cancer risks following diagnostic and therapeutic radiation exposure in children. Pediatr Radiol. 2006 Sep;36 Suppl 2(Suppl 2):121-5. PubMed PMID: 16862418.

[6]. American Dental Association Council on Scientific Affairs. The use of dental radiographs: update and recommendations. J Am Dent Assoc. 2006 Sep;137(9):1304-12. PubMed PMID: 16946440.

[7]. Memon A, Rogers I, Paudyal P, Sundin J. Dental X-Rays and the Risk of Thyroid Cancer and Meningioma: A Systematic Review and Meta-Analysis of Current Epidemiological Evidence. Thyroid. 2019 Nov;29(11):15721593. PubMed PMID: 31502516.

[8]. Mantuano ND, Canevaro LV, Maurício CL, CA S. Assessment of dose in thyroid and salivary glands in dental radiology using thermoluminiscent do- 
simetry. International nuclear Atlantic conference 2011.

[9]. Burke K, Sutton D. Optimization and deconvolution of lithium fluoride TLD-100 in diagnostic radiology. Br J Radiol. 1997 Mar;70:261-71. PubMed PMID: 9166051.

[10]. Diagnostic reference levels in medical imaging: review and additional advice. Ann ICRP. 2001;31(4):33-52. PubMed PMID: 12685758.

[11]. Mortazavi SM, Shareghi A, Ghiassi-Nejad M, Kavousi A, Jafari-Zadeh M, Nazeri F, Mozdarani H (2004). The need for national diagnostic reference levels: Entrance surface dose measurement in intraoral radiography. Iran J Radiat Res 15(2):127-33.

[12]. Poppe B, Looe HK, Pfaffenberger A, Eenboom F, Chofor N, Sering M, Rühmann A, Poplawski A, Willborn K. Radiation exposure and dose evaluation in intraoral dental radiology. Radiat Prot Dosimetry. 2007;123(2):262-7. PubMed PMID: 16971397.

[13]. Sheikh S, Bhoweer AK, Arya S, Arora G. Evaluation of surface radiation dose to the thyroid gland and the gonads during routine full-mouth intraoral periapical and maxillary occlusal radiography. Contemp Clin Dent. 2010 Apr;1(2):83-7. PubMed PMID: 22114389.

[14]. Jibiri N, Adeleye B, Kolude B (2017). Radiation dose to the thyroid, eyes and parotid glands of patients undergoing intra-oral radiographic procedures in a teaching hospital in Ibadan, Oyo state Nigeria.Int J Radiat Res. 15(1):101-106. 